\section{The Impact of Interior Plants in University Classrooms on Student Course Performance and on Student Perceptions of the Course and Instructor}

\author{
Jennifer S. Doxey ${ }^{1}$ and Tina Marie Waliczek ${ }^{2,4}$ \\ Department of Agriculture, Texas State University, 601 University Drive, \\ San Marcos, TX 78666
}

\author{
Jayne M. Zajicek ${ }^{3}$ \\ Department of Horticultural Sciences, Texas A\&M University, College \\ Station, TX 77843-2133
}

Additional index words. interiorscape, human issues in horticulture, course evaluation, instructor evaluation, academic responses, instructional ratings, houseplant

\begin{abstract}
The main objective of this research was to investigate the impact of plants within a university classroom setting on course performance and on student perceptions of the course and instructor. The study was designed to include a minimum of two classes of the same coursework taught by the same professor in the same room during one semester. Three sets of two classes each and 385 students were included within the study. Throughout the semester, the experimental class of students was treated by including an assortment of tropical plants within the classroom. Plants were not present in the control classroom of the study. The official university course and instructor evaluation survey was administered at the end of the semester. Additionally, each student provided demographic data, including class rank, gender, and ethnicity. To measure course performance, the professor for each course reported each student's grade for the course. No statistically significant differences were found in comparisons of grades/student course performance $(P=0.192)$. However, statistically significant differences were found in comparisons of overall course and instructor evaluation scores of treatment and control groups $(P=0.065)$. Statistically significant differences were found in comparisons of the individual courses/classrooms between control and treatment groups on statements in subsections of the course and instructor evaluation survey, including the areas of "learning," "enthusiasm (of instructor)," and "organization (of instructor)." In these comparisons of the treatment and control groups, the differences that were most apparent were in students who had class in the classroom that was windowless and stark. The plants appeared to have the greatest impact on students in the room that was void of other natural elements.
\end{abstract}

In the 1700 s, interior plants were considered to be capable of suffocating a person while they slept. Still, people kept plants in their homes despite the warnings (Gowan, 1987), demonstrating an inherent desire for plants. Today, an urbanized lifestyle has led to people spending $80 \%$ or more of their time in indoor settings (Fjeld et al., 1998). Many individuals and businesses continue to enhance their homes or offices with interior plants (Dravigne et al., 2008). Research has suggested that interior plants may offer some psychological and restorative values such as reduced tension (Ulrich et al., 1991), better

\footnotetext{
Received for publication 20 Oct. 2008. Accepted for publication 18 Dec. 2008.

${ }^{1}$ Graduate student.

${ }^{2}$ Associate Professor.

${ }^{3}$ Professor.

${ }^{4}$ To whom reprint requests should be addressed; e-mailtc10@txstate.edu.
}

coping mechanisms (Lohr and PearsonMims, 2000), and increased ability for concentration and attention (Taylor et al., 2001). A recent study found that employees in offices with plants rated their job satisfaction more positively when compared with employees in offices with no plants present (Dravigne et al., 2008). Research has found that interior plants can reduce eye irritation and stress, motivate employees, improve concentration, and even reduce air impurities (Vitiello, 2001). Plants appeared to have a positive effect on headaches and fatigue and hoarseness; even dry facial skin was reported with less incidence when plants were introduced to offices (Fjeld et al., 1998; Laviana et al., 1983).

The benefits of interior plants have been shown to positively impact stress and productivity. Reaction time on the computer improved by $12 \%$ and a lower systolic blood pressure was measured when plants were placed in a computer laboratory along with people's reports of experiencing greater attentiveness (Lohr et al., 1996). On one survey of office employees and facilities managers, only $10 \%$ of respondents thought that their offices could be improved with plants, yet $60 \%$ of office workers liked having plants around their desk. This was interesting in that it was a higher percentage than the $50 \%$ who rated the necessity of good technology as a priority (Vitiello, 2001).

Research has focused on the types of interior environments that promote good teaching and learning (Think, 2003) and found that attention paid to the factors of "light, acoustics, ventilation and ergonomics all contribute to a positive experience for faculty and students" (p. 2). Windows that provided natural lighting were important (Think, 2003), and rooms with access to only artificial light have been associated with "building sickness" (Robertson et al., 1989), which can lead to workrelated headaches and lethargy. Although the subject of student and instructor preference in classroom attributes is limited, one study found that professors and students rated positive physical characteristics in classrooms similarly (Douglas and Gifford, 2001). Results found that classrooms with seating arranged to promote interaction among students, views of outdoor areas, and comfortable seating were preferred by both students and faculty (Douglas and Gifford, 2001). Using a survey of students (Dinsmore, 2003), a middle school teacher studied the perceived effects of plants, lighting, and music on students' behaviors while in the classroom. When asked if these three variables affected their learning, $43 \%$ of students responded positively to the presence of plants saying it created a more comfortable atmosphere (Dinsmore, 2003). These numbers supported the teacher's personal observations.

Research in schools has found that plants benefit the classroom aesthetically and provide oxygen while absorbing toxins (Hart, 1999). In children with attention deficit disorder (ADD), more severe ADD symptoms were seen in children when the interior classroom environment was windowless and void of natural elements (Taylor et al., 2001). A study of university students found that recovery from stress was shown to be greater for those who had plants present during testing (Russell and Uzzell, 1999).

This research supports that "A premium should be placed on ensuring that all teaching environments provide the best possible conditions to stimulate learning. The teaching environment affects how students rate their course experience, and often affects the comfort level of not only the students, but also the instructor within the classroom" (Think, 2003). Studies have shown that interior natural elements are important environmental factors for universities that can cause students to feel more comfortable, stimulating social interaction and more time spent on campus (Wiers-Jenssen et al., 2002).

The purpose of this study was to determine if interior plants in university classrooms had 
an impact on student course performance and on student perceptions of the course and the instructor.

\section{Materials and Methods}

Study site. The study took place at a southern university with an enrollment of $\approx 28,000$ students at the time of the study. The main campus has 225 buildings with some dating back to the origin of the campus in 1903 and some new buildings and classrooms that were built in recent years to accommodate the growing enrollment. The student enrollment is diverse with a minority student population of over $30 \%$.

Instructors and courses. At the beginning of the spring semester, instructors were selected from the course catalog who met the criteria of teaching the same course in the same room with the same course material to two or more separate groups of students. These instructors were invited to participate in the study. Instructors were offered free weekly floral designs delivered to their office throughout the semester as an incentive to participate in the study. Three professors agreed to participate. One taught two sections of an introductory psychology course. Another professor taught two sections of a sophomorelevel psychology course, and the third taught two sections of an introductory sociology course. All instructors held doctorates in the fields in which they were teaching, and all taught courses in the department for at least 3 years.

All six classes were offered during the morning hours, and for uniformity within the study, all control classes met first. However, treatment and control classes for each instructor did not necessarily meet on the same weekdays, although for each course, they all met for the same amount of time (50 min or $1 \mathrm{~h} 15 \mathrm{~min}$ ).

Enrollment in the treatment and control classes for each course was not controlled and varied somewhat between groups. The introductory psychology course included 57 students in the treatment group and 37 students in the control group, whereas the sophomorelevel psychology course included 45 students in the treatment group and 44 students in the control group. The introductory sociology course included 97 students in the treatment group and 104 students in the control group. Therefore, because the classes and instructors were not randomly chosen or assigned, results of the study may not be generalized to the overall population.

Plants. An assortment of plants was used in each classroom with the logistics of the room taken into consideration. Larger plants used included Chrysalidocarpus lutescens (Areca Palm), Ficus elastica (Rubber Tree), and Dracaena marginata (Dragon Plant). For hanging plants, Chlorophytum comosum (Spider Plant), Hedera helix (English Ivy), and Peperomia obtusifolia (Baby Rubber Tree Peperomia) were used. An assortment of foliage of various colors, sizes, and textures such as Spathiphyllum wallisii 'Mauna Loa' (Peace Lily), small Kalanchoe blossfeldiana (Kalanchoe), and Epipremnum aureum (Pothos) were used interchangeably.

Classrooms and plant placement. All classes met within two buildings on campus. In all classrooms, focus was given to the front of the classroom for plant placement (Figs. 1 and 2), although an attempt was made to place other plants in appropriate spots around the classroom because visibility of the plants could have been limited for some students given their seating location. Student seating was not assigned, and students had the option in all classes of sitting in any available seat throughout the semester. The introductory psychology course met in a classroom on the second floor of the Psychology Building and seated $\approx 80$ students. The room received morning sunlight through a wall of windows that faced south and had a view of large trees that grew directly outside. Spacious areas within the room allowed for ample opportunity
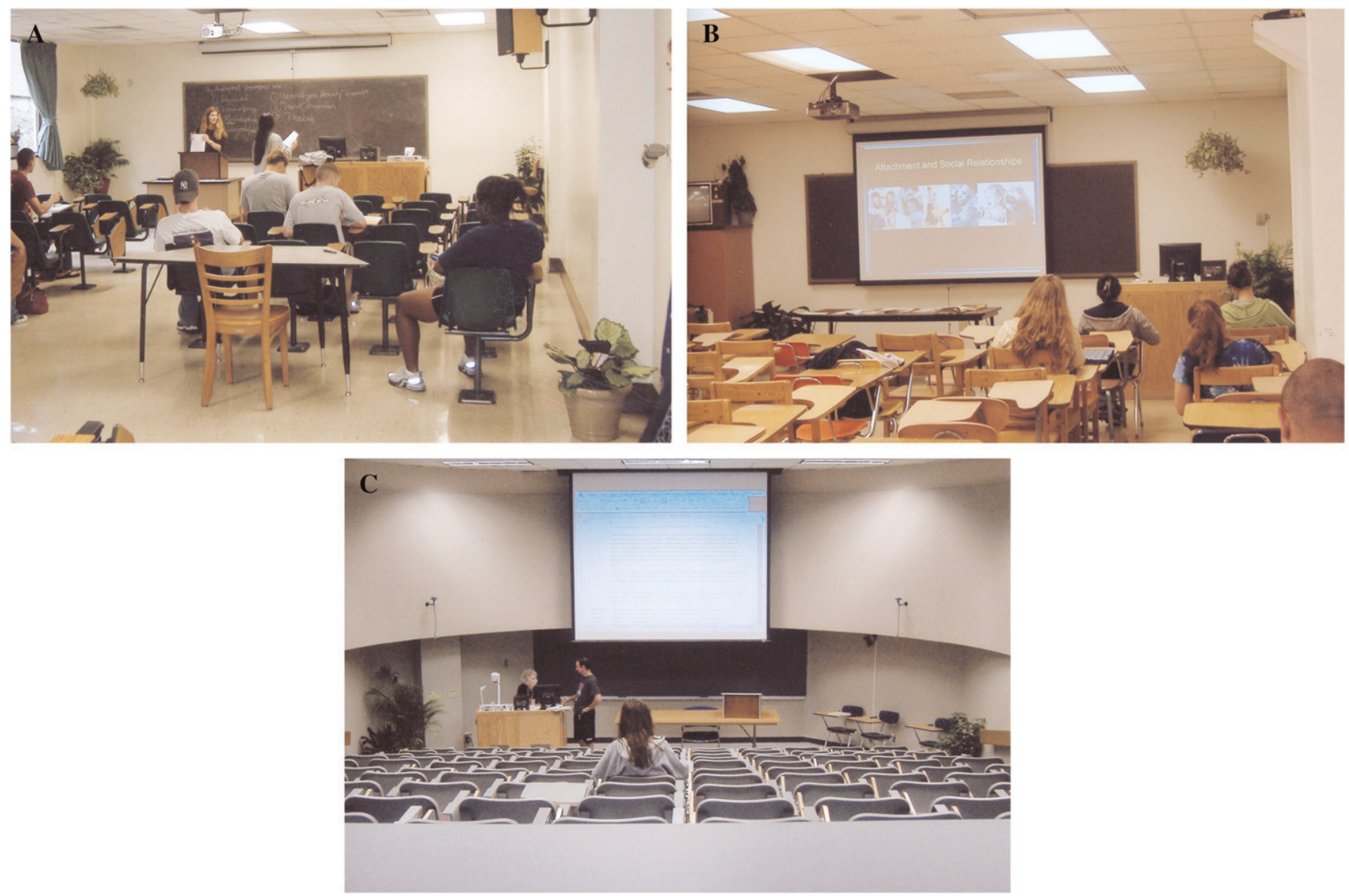

Fig. 1. Photographs of each of the treatment classrooms included in the study of the impact of interior plants in university classrooms on student course performance and on perceptions of the course and instructor. The room in A seated 80 students, whereas the room in $\mathbf{B}$ seated 60 students. The auditorium in $\mathbf{C}$ seated 121 students. 

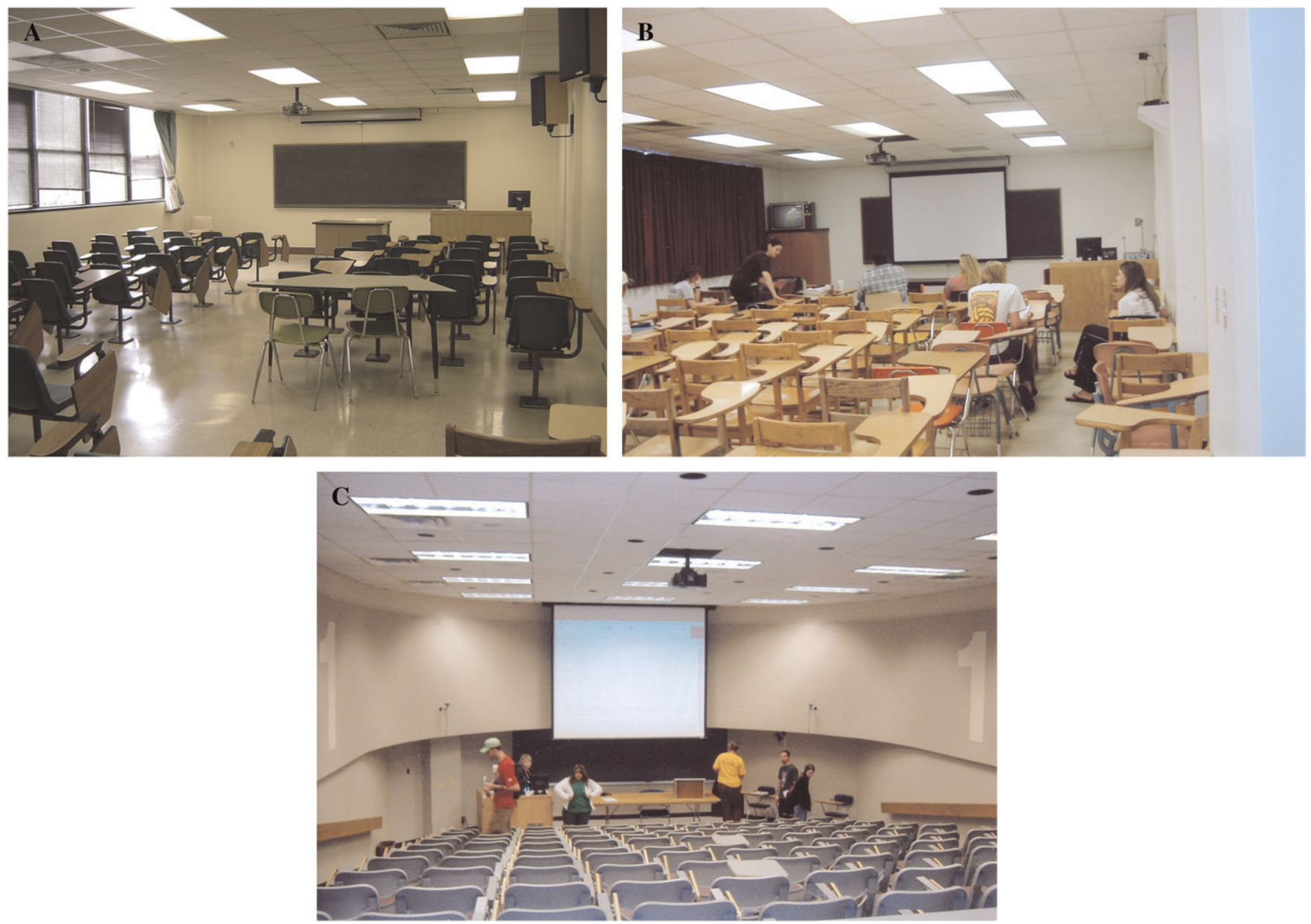

Fig. 2. Photographs of each of the control classrooms included in the study of the impact of interior plants in university classrooms on student course performance and on perceptions of the course and instructor. The room in A seated 80 students, whereas the room in $\mathbf{B}$ seated 60 students. The auditorium in $\mathbf{C}$ seated 121 students.

to place a variety of greenery throughout the classroom (Fig. 1A).

The sophomore-level psychology course classroom was a third floor classroom in the Psychology Building (Fig. 1B). The room had windows facing north that viewed the tops of trees. The classroom was cramped with furniture and media equipment crowded aisles. A drape dangled from a window during a portion of the semester and often the drapes hid much of the window view of the trees outside. One to three plants were hung in the front or on the side of the room from the ceiling tiles. Larger plants were also placed on the floor and table surfaces in the front of the classroom. The main entranceway into the classroom was at the back of the classroom, so a floor plant was often strategically placed to be seen as students entered the room (Fig. $1 B)$. The room held seating for $\approx 60$ students.

The introductory sociology course classroom was a modern but stark, windowless auditorium with limited floor space. The room seated over 100 students. Three to four larger-sized plants were placed on the floor in the front of the classroom on the right and on the left side of the room where they would not interfere with instruction but could be viewed by students (Fig. 1C).
Plants were placed and removed quickly and anonymously between classes. Students in the treatment and control groups were not informed of the study and its objectives. When plants showed stress, they were replaced with healthier specimens.

Course and instructor evaluation instrumentation. A consent form was distributed and collected that allowed for students to volunteer anonymous information for the research, and the research was approved by the university Internal Review Board. Students were offered a packet of seeds or a candy bar as an incentive to participate in the study. Professors provided all students with a code number to use when responding instead of their name so that all information provided remained anonymous.

Surveys were distributed in each treatment and control classroom during the last 2 weeks of the semester by the researchers. Demographic data, including class rank (freshman, sophomore, junior, senior), gender, and ethnicity, were gathered. Questions from the official university course evaluation survey were used to collect information on student perceptions of the course and the instructor. Twenty-two questions covered the categories of "learning," "enthusiasm," "orga- nization," "individual rapport," "examinations," "assignments," and "student and course characteristics." Students were instructed to rate each of the 22 statements by choosing responses rated on a Likert-type scale (Likert, 1967). The five responses were $5=$ "strongly agree," 4 = "agree," $3=$ "neutral," 2 = "disagree," and 1 = "strongly disagree." The reliability of the overall instrument used for this study was determined using the Cronbach's alpha reliability test and was found to be 0.84 for this study indicating suitable reliability (Gall et al., 2006).

Course performance data. Course grade was determined by the instructors of each course and was reported to researchers by each instructor. Course grade measured course achievement on the traditional 4-point scale $(\mathrm{A}=4.0, \mathrm{~B}=3.0, \mathrm{C}=2.0, \mathrm{D}=1.0$, and $\mathrm{F}=0.0)$. The university involved in the study does not use the plus and minus system of grading.

Scoring and data analysis. The section of the instrument that measured student perceptions of the course and instructor were scored by allocating 5 points for the most positive answers and 1 point for most negative answers given by each student on the Likert scale (Likert, 1967). Responses were reversecoded when the most positive answer was initially allocated the least amount of points. 
Therefore, with 22 questions in total, each student earned a score that ranged from 22 to 110. Individual scores were tabulated by the primary researcher for the study and entered into a Microsoft Excel ${ }^{\mathrm{TM}}$ spreadsheet (Seattle, WA).

The data collected were analyzed using the Statistical Package for the Social Sciences (SPSS) for Windows Release $11.5^{\mathrm{TM}}$ (Chicago, IL). Statistical procedures included descriptive statistics, frequencies, and analysis of variance tests to determine differences between overall grades and scores, categories of responses, individual statements, and individual course comparisons. The a priori alpha level was set at 0.10 , which is considered suitable for research in the social and behavioral sciences (Bennett, 1995; Borg and Gall, 1989; Kaplan, 1987).

\section{Results and Discussion}

The control group included $48.1 \%$ (185) of respondents, whereas the treatment group included $51.9 \%$ (200) of the sample. Demographic background of the control and treatment groups was compared and found to be statistically similar for gender $(P=0.373)$, ethnicity $(P=0.606)$, and overall university grade point average (GPA; $P=0.730)$. Statistically significant differences were found in the area of class rank (freshman, sophomore, junior, senior) $(P=0.097)$ with the treatment group having more freshman when compared with the control group (34.5\% versus $28.6 \%)$ and the control group having more seniors when compared with the treatment group (14.1\% versus $8 \%)$. Numbers of sophomores were similar for the treatment and control groups $(36 \%$ versus $36.2 \%$ ) as were percent juniors included in each group ( $20 \%$ versus $19.5 \%$ ). Past research has found that seniors tend to rate courses more positively when compared with other class ranks (Frey et al., 1975); therefore, researchers were not concerned with the control group having more seniors and fewer freshman because it would not benefit the treatment group in terms of biasing the variables of interest.

The overall sample included 137 males and 246 females (and two respondents who did not report gender). Most students were undergraduate freshmen or sophomores $(67.8 \%)$ and white (69.1\%). Although this sample was similar to the overall population of students at the university, the sample was self-selected by the volunteering instructors of the courses and the students who agreed to participate in the study and therefore may differ from the overall target comparison population (Frankel, 1983).

Course performance. The first objective of the study was to compare final course grades of students in classrooms that had plant material present during instruction with final course grades of students in classrooms with no plant material present. Course performance was analyzed by comparing grades issued by the course instructors on a 4-point scale. An analysis of variance compared the treatment and control groups' grades and no statistically significant differences were found $(P=0.192$; Table 1). Therefore, when looking at the overall sample of students, plants did not appear to distract students nor benefit them during instruction. Research has found that plants may help to improve concentration (Taylor et al., 2001; Vitiello, 2001) and task performance (Shibata and Suzuki, 2004), which would, in turn, improve grades. However, these overall findings did not appear to support these studies in comparisons of the overall sample.

Course and instructor evaluation scores. An analysis of variance compared the treatment and the control groups' overall scores concerning perceptions of the course and the instructor and found statistically significant differences $(P=0.065$; Table 1$)$. The treatment group scores were 1.52 points higher than the control group scores $(82.13$ versus 80.61 ). The range of scores was much narrower for the treatment group with the minimum and maximum scores being 59 and 100 compared with the control group's minimum and maximum scores of 29 and 100. Research findings in areas of office work have shown that plants can improve perceptions of the work environment (Dravigne et al., 2008; Fjeld et al., 1998; Lohr et al., 1996). This research supports other studies with undergraduate students that found that mood was improved in rooms that contained a plant (Shibata and Suzuki, 2004).

Statements on the course and instructor evaluation inventory were analyzed individually to see where differences were occurring in how respondents answered. Of the 22 statements, 10 individual statements were found to be statistically significantly different between treatment and control groups (Table 2). All of the statistically significant statements were rated more positively by students in the treatment group. It was interesting to note that all of the categories that related directly to in-class learning had some, and sometimes all of the statements showing statistically significantly differences, including the categories of "learning," "enthusiasm," "organization," and "student and course characteristics." Categories that had statements that were less connected with daily in-class situations, including "individual rapport," "examinations," and "assignments," had no statements that were statistically significantly different in comparisons between the control and treatment groups (Table 2).

All four statements in the category of "learning" showed statistically significant differences (Table 2). Statistical significance was found in mean score comparisons of the treatment and control group responses to the statement, "I found the course challenging and stimulating" ( $P=0.096$; Table 2$)$. Mean scores for the treatment group were higher than those for the control group (4.04 versus 3.93). Mean scores were also statistically significantly higher for the treatment group on the statement, "I have learned something I consider valuable" ( $P=0.094 ; 4.29$ versus 4.18; Table 2). There were differences in treatment group versus control group responses to the statement, "My interest in the subject has increased as a consequence of this course" $(P=0.014$; Table 2). More students in the treatment group $(8.5 \%)$ responded as agreeing or strongly agreeing to the statement when compared with the respondents in the control group. Nearly $11 \%$ $(10.8 \%)$ of the control group disagreed or strongly disagreed with the statement compared with $2.5 \%$ negative responses from the treatment group. Additionally, statistically significant differences were found concerning the "learning" statement, "I have learned and understood the subject materials in this course" $(P=0.038)$. The treatment group more often agreed or strongly agreed $(6.5 \%)$ when compared with control group responses (Table 2). In the control group, $3.9 \%$ of students indicated "disagree" or "strongly disagree" compared with $2.0 \%$ in the treatment group who indicated only "disagree."

Both statements in the "enthusiasm" category were found to be statistically significantly different in comparisons between treatment and control group responses. Treatment group mean scores showed more positive responses on the statement, "Instructor's style of presentations held my interest during most of the class time" when compared with control group mean scores $(P=$ $0.059 ; 4.13$ versus 3.96 ; Table 2 ). On the "enthusiasm" statement, "Instructor seemed interested in teaching the course," the treatment group had 4\% more responses as "agree" or "strongly agree" in comparison with the control group's responses on the same

Table 1. Analysis of variance comparisons of overall treatment and control groups' instructor-issued end-

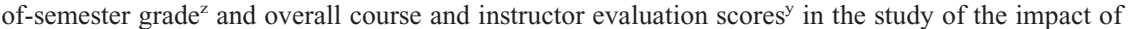
interior plants in university classrooms on student course performance and on perceptions of the course and instructor.

\begin{tabular}{|c|c|c|c|c|c|c|}
\hline Participant group & Sample size (no.) & Mean $^{z}$ & SD & df & $\mathrm{F}$ & $P$ \\
\hline \multicolumn{7}{|l|}{ Course grade ${ }^{z}$} \\
\hline Treatment & 190 & 2.65 & 1.017 & 1 & 1.706 & 0.192 \\
\hline Control & 176 & 2.51 & 0.985 & & & \\
\hline \multicolumn{7}{|c|}{ Overall course and instructor evaluation scores $\mathrm{s}^{\mathrm{y}}$} \\
\hline Treatment & 200 & 82.13 & 8.063 & 1 & 3.428 & $0.065^{*}$ \\
\hline Control & 185 & 80.61 & 10.120 & & & \\
\hline
\end{tabular}

${ }^{\mathrm{z}}$ Grades were issued on a traditional 4-point scale by instructor with $\mathrm{A}=4.0, \mathrm{~B}=3.0, \mathrm{C}=2.0, \mathrm{D}=1.0$, and $\mathrm{F}=1.0$.

${ }^{y}$ Scores ranged from 22 to 110 . Twenty-two statements were rated on a 1 to 5 scale with 5 being the most positive response and 1 being the most negative response.

${ }^{*}$ Statistically significant at the 0.10 level. 
Table 2. Analysis of variance comparing treatment and control groups' individual statement response means $\mathrm{s}^{\mathrm{z}}$ on the course and instructor evaluation instrument in the study of the impact of interior plants in university classrooms on student course performance and on perceptions of the course and instructor.

\begin{tabular}{|c|c|c|c|c|c|c|}
\hline Participant group & Sample size (no.) & Mean $^{z}$ & SD & $\overline{d f}$ & $\bar{F}$ & $P$ \\
\hline \multicolumn{7}{|l|}{ Learning } \\
\hline Treatment & 200 & 4.04 & 0.562 & 1 & 2.778 & $0.096^{*}$ \\
\hline Control & 185 & 3.93 & 0.676 & & & \\
\hline Treatment & 200 & 4.29 & 0.554 & 1 & 1.197 & $0.094 *$ \\
\hline Control & 185 & 4.18 & 0.741 & & & \\
\hline \multicolumn{7}{|c|}{ My interest in the subject has increased as a consequence of this course. } \\
\hline Treatment & 200 & 4.10 & 0.780 & 1 & 6.154 & $0.014 * *$ \\
\hline Treatment & 200 & 4.18 & 0.610 & 1 & 4.318 & $0.038 * *$ \\
\hline Control & 184 & 4.04 & 0.723 & & & \\
\hline \multicolumn{7}{|l|}{ Enthusiasm } \\
\hline \multicolumn{7}{|c|}{ Instructor's style of presentations held my interest during most of the class time. } \\
\hline Treatment & 200 & 4.13 & 0.858 & 1 & 3.583 & $0.059^{*}$ \\
\hline Control & 185 & 3.96 & 0.881 & & & \\
\hline \multicolumn{7}{|c|}{ Instructor seemed interested in teaching the course. } \\
\hline Treatment & 200 & 4.35 & 0.640 & 1 & 6.647 & $0.010^{* *}$ \\
\hline Control & 185 & 4.15 & 0.900 & & & \\
\hline The assignments in & plained. & & & & & \\
\hline Treatment & 199 & 4.29 & 0.684 & 1 & 2.556 & 0.111 \\
\hline Control & 185 & 4.17 & 0.773 & & & \\
\hline Instructor spoke cl & & & & & & \\
\hline Treatment & 200 & 4.51 & 0.558 & 1 & 7.024 & $0.008 * *$ \\
\hline Control & 185 & 4.34 & 0.728 & & & \\
\hline Instructor spoke at & peed. & & & & & \\
\hline Treatment & 200 & 4.39 & 0.685 & 1 & 1.027 & 0.312 \\
\hline Control & 185 & 4.31 & 0.699 & & & \\
\hline Individual rappor & & & & & & \\
\hline Instructor made $\mathrm{m}$ & in seeking help/advi & of class & & & & \\
\hline Treatment & 200 & 4.21 & 0.810 & 1 & 0.430 & 0.512 \\
\hline Treatment & 197 & 3.78 & 0.838 & 1 & 0.000 & 0.992 \\
\hline Control & 184 & 3.78 & 0.866 & & & \\
\hline Feedback on grade & useful to me. & & & & & \\
\hline Treatment & 198 & 3.74 & 0.806 & 1 & 0.343 & 0.558 \\
\hline Control & 183 & 3.79 & 0.858 & & & \\
\hline Methods on evalua & rk were fair. & & & & & \\
\hline Treatment & 198 & 4.21 & 0.639 & 1 & 0.058 & 0.809 \\
\hline Control & 184 & 4.19 & 0.726 & & & \\
\hline Examinations teste & $t$ as emphasized by $t$ & & & & & \\
\hline Treatment & 198 & 4.30 & 0.681 & 1 & 0.797 & 0.373 \\
\hline Control & 185 & 4.23 & 0.755 & & & \\
\hline Examinations refle & tent covered. & & & & & \\
\hline Treatment & 199 & 4.29 & 0.707 & 1 & 0.004 & 0.947 \\
\hline Control & 185 & 4.29 & 0.765 & & & \\
\hline Assignments & & & & & & \\
\hline Required readings & & & & & & \\
\hline Treatment & 200 & 3.69 & 0.882 & 1 & 1.030 & 0.311 \\
\hline Control & 185 & 3.59 & 0.963 & & & \\
\hline Required texts wer & & & & & & \\
\hline Treatment & 200 & 3.68 & 0.950 & 1 & 0.743 & 0.389 \\
\hline Control & 184 & 3.59 & 1.041 & & & \\
\hline Student and cour & & & & & & \\
\hline Level of interest in & ore this course. & & & & & \\
\hline Treatment & 200 & 2.98 & 0.961 & 1 & 2.834 & $0.093 *$ \\
\hline Control & 184 & 2.81 & 1.020 & & & \\
\hline Level of interest a & & & & & & \\
\hline Treatment & 200 & 3.68 & 0.890 & 1 & 5.483 & $0.020^{* *}$ \\
\hline Control & 185 & 3.45 & 1.047 & & & \\
\hline
\end{tabular}

${ }^{2}$ Statements were rated on a 1 to 5 scale with 5 being the most positive response and 1 being the most negative response.

"Statistically significant at the 0.10 level.

${ }^{* * *}$ Statistically significant at the 0.05 level. 
statement $(P=0.015$; Table 2$)$. Only one person $(0.5 \%)$ of the 200 responses indicated a negative "disagree" in the treatment group, whereas three persons $(1.6 \%)$ of the 185 control group responses indicated they disagreed, two of those being "strongly disagree" $(P=0.015$; Table 2$)$.

Two of four statements in the "organization" category were found to be statistically significant in comparisons of the treatment and control group responses. The statement, "Instructor's explanations were clear" had statistically significant differences in comparisons of the treatment to the control group responses $(P=0.010$; Table 2$)$. Over $5 \%$ more of the treatment group responded positively to the statement, "The assignments were carefully explained" when compared with control group responses. Quantitative response to "Instructor spoke clearly" was $4 \%$ more positive $(P=0.008)$ within the treatment group (Table 2).

When rating statements concerning levels of interest at the start of the course versus the levels at the end of the course, statistically significant differences were found in the levels of interest students perceived they had in the subject before the course began $(P=0.093$; Table 2) and at the time of the course and instructor evaluation $(P=0.020$; Table 2). On both statements, the treatment group rated the statements more positively when compared with the control group. However, the differences between groups were much more evident on how students rated their interest levels at the end of the course with almost $9 \%$ more students in the treatment group rating their interest levels as "high" or "very high" when compared with the control group $(58.5 \%$ in the treatment group versus $50.3 \%$ in the control group).

These overall findings in comparisons of individual statements are compatible with research that found plants improve the classroom aesthetically (Hart, 1999) and that 43\% of young students felt the presence of plants creates a more comfortable learning environment (Dinsmore, 2003).

Individual classroom/course comparisons. Researchers were interested in comparing individual classrooms/courses. Demographic comparisons were made before comparisons and no differences were found in comparisons of ethnicity $(P=0.338)$, class rank $(P=$ $0.135)$, or GPA $(P=0.242)$. Statistically significant differences were found in comparisons of gender with the sophomore-level psychology course having more females $(76.1 \%)$ in comparison with the introductory psychology course $(61.7 \%$ female $)$ or the introductory sociology course ( $60.2 \%$ female) $(P=0.028)$. The limitations these differences presented in the data set were considered during interpretation of the analysis.

When comparisons were made between classrooms/courses of students, no differences were found in comparisons of treatment and control groups of students in the introductory psychology course in the well-maintained second floor classroom in comparisons of student course grades $(P=0.480)$ or in comparisons of course and instructor evaluation scores $(P=0.964)$. The introductory psychology course met in a sunny classroom with ample room for interior plants, windows, and a view of trees. Window views of green leaves on trees outside this classroom may have influenced students and made the influence of the plants in the classroom less pronounced. This would support other research stating that students preferred classrooms with views of the outdoors (Douglas and Gifford, 2001)

Analysis of the treatment and control group of students in the sophomore-level psychology course in the third floor cramped classroom revealed differences in distribution of course grades $(P=0.005$; Table 3$)$ with treatment group grades averaging higher when compared with the control group. Grade distribution for the course revealed $21.9 \%$ more grades of " $\mathrm{A}$ " in the treatment group when compared with the control group, $8.3 \%$ more grades of " $\mathrm{B}$ " in the treatment group than in the control group, and $16.5 \%$ more responses of " $\mathrm{C}$ " in the control group when compared with the treatment group.

No statistically significant differences $(P=$ 0.705 ) were found in the overall course and instructor evaluation scores between the treatment and control groups in the third floor cramped classroom with windows. However, in interviews with the professor of the sophomore-level psychology classes, she stated that she felt attendance was better, class participation was better, and class average on most tests was higher in the class with plants.

Window views in the sophomore-level psychology classroom were often blocked by dark drapes. The green view of the tops of trees was not as lush and bright from the third floor as were the views from the second floor on the other side of the building in the introductory psychology classroom. Therefore, it is possible indoor plants may have had a slightly greater effect on course grades in the third floor classroom when compared with the second floor classroom. Additionally, although research indicates that gender and grades are not necessarily correlated (MeCornack and McLeod, 2005), it may be important to note that this course and class- room had a statistically significantly greater number of females in comparison with the other courses and classrooms that could have impacted results.

There were no statistically significant differences found in overall course grades in comparisons of the treatment and control groups of students enrolled in the introductory sociology class held in the large auditorium $(P=0.750)$. However, there were differences in the overall course and instructor evaluation scores $(P=0.049$; Table 3$)$ and several statistically significant differences in comparisons of students' responses to individual statements on the course and instructor evaluation instrument (Table 4). Statistically significant differences were found on 12 of the 22 survey questions, including all questions in the categories of "learning," "enthusiasm," and "organization" (Table 4). As shown in previous comparisons of the overall sample, those categories that were less influenced by in-class interactions ("individual rapport," "examinations," and "assignments") had nearly all statements lacking statistically significant differences in comparisons of the treatment and control groups (Table 4). Students in the treatment group did rate the statement, "Required readings were useful to me" more positively when compared with the control group $(P=0.093$; Table 4) as well as their level of interest in the course at the time of the evaluation as being higher $(P=0.025$; Table 4$)$.

The introductory sociology class had no windows, was modern and in good repair, but stark. It seated 121 people in an auditorium-style room that was painted white. Plants appeared to have contributed to the comfort, attention, and concentration of students in the stark, windowless auditorium more than in the psychology classes, which had windows and a view of trees with green leaves. These results supported research on worker productivity that found that, in offices with plants, productivity and attentiveness increased, whereas blood pressure and mental fatigue decreased (Lohr et al., 1996).

Instructor interviews. A brief interview was conducted with each participating professor to assess if plant material affected the

Table 3. Statistically significant analysis of variance comparisons of course grades ${ }^{\mathrm{z}}$ and overall course and instructor evaluation scores ${ }^{y}$ of treatment and control groups for the sophomore-level psychology class and introductory sociology class in the study of the impact of interior plants in university classrooms on student course performance and on perceptions of the course and instructor.

\begin{tabular}{|c|c|c|c|c|c|c|}
\hline Participant group & $\begin{array}{c}\text { Sample size } \\
\text { (no.) }\end{array}$ & Mean $^{\text {z,y }}$ & SD & df & $\mathrm{F}$ & $P$ \\
\hline \multicolumn{7}{|c|}{ Sophomore-level psychology } \\
\hline \multicolumn{7}{|l|}{ Course grades ${ }^{\mathrm{z}}$} \\
\hline Treatment & 44 & 3.14 & 0.795 & 1 & 8.353 & $0.005^{* *}$ \\
\hline Control & 39 & 2.62 & 0.847 & & & \\
\hline \multicolumn{7}{|c|}{ Introductory sociology } \\
\hline \multicolumn{7}{|c|}{ Overall course and instructor evaluation scores ${ }^{\mathrm{y}}$} \\
\hline Treatment & 97 & 80.78 & 8.502 & 1 & 3.914 & $0.049 * *$ \\
\hline Control & 104 & 78.25 & 9.574 & & & \\
\hline
\end{tabular}

${ }^{\mathrm{z}}$ Grades were issued on a traditional 4-point scale by instructor with $\mathrm{A}=4.0, \mathrm{~B}=3.0, \mathrm{C}=2.0, \mathrm{D}=1.0$, and $\mathrm{F}=1.0$. ${ }^{y}$ Scores ranged from 22 to 110 . Twenty-two statements were rated on a 1 to 5 scale with 5 being the most positive response and 1 being the most negative response.

${ }^{* *}$ Statistically significant at the 0.05 level. 
Table 4. Analysis of variance comparisons of treatment and control groups' individual statement response means ${ }^{z}$ from the course and instructor evaluation instrument for students in the introductory sociology course in the study of the impact of interior plants in university classrooms on course performance and on perceptions of the course and instructor.

\begin{tabular}{|c|c|c|c|c|c|c|}
\hline Participant group & Sample size (no.) & Mean $^{\mathrm{z}}$ & SD & $\mathrm{df}$ & $\mathrm{F}$ & $P$ \\
\hline \multicolumn{7}{|l|}{ Learning } \\
\hline \multicolumn{7}{|c|}{ I found the course challenging and stimulating. } \\
\hline Treatment & 97 & 4.09 & 0.631 & \multirow[t]{2}{*}{1} & \multirow[t]{2}{*}{6.128} & \multirow[t]{2}{*}{$0.014 * *$} \\
\hline Control & 104 & 3.87 & 0.669 & & & \\
\hline \multicolumn{7}{|c|}{ I have learned something I consider valuable. } \\
\hline Treatment & 97 & 4.25 & 0.613 & \multirow[t]{2}{*}{1} & \multirow[t]{2}{*}{4.961} & \multirow[t]{2}{*}{$0.027 * *$} \\
\hline Control & 104 & 4.04 & 0.709 & & & \\
\hline \multicolumn{7}{|c|}{ My interest in the subject has increased as a consequence of this course. } \\
\hline Treatment & 97 & 4.07 & 0.820 & \multirow[t]{2}{*}{1} & \multirow[t]{2}{*}{5.759} & \multirow[t]{2}{*}{$0.017 * *$} \\
\hline Control & 104 & 3.75 & 1.059 & & & \\
\hline \multicolumn{7}{|c|}{ I have learned and understood the subject materials in this course. } \\
\hline Treatment & 97 & 4.18 & 0.595 & \multirow[t]{2}{*}{1} & \multirow[t]{2}{*}{4.075} & \multirow[t]{2}{*}{$0.045 * *$} \\
\hline Control & 103 & 3.98 & 0.754 & & & \\
\hline \multicolumn{7}{|l|}{ Enthusiasm } \\
\hline \multicolumn{7}{|c|}{ Instructor style of presentations held my interest during most of the class time. } \\
\hline Treatment & 97 & 4.07 & 0.927 & \multirow[t]{2}{*}{1} & \multirow[t]{2}{*}{4.486} & \multirow[t]{2}{*}{$0.035 * *$} \\
\hline Control & 104 & 3.80 & 0.907 & & & \\
\hline \multicolumn{7}{|c|}{ Instructor seemed interested in teaching the course. } \\
\hline Treatment & 97 & 4.62 & 0.567 & \multirow[t]{2}{*}{1} & \multirow[t]{2}{*}{8.778} & $0.003 * *$ \\
\hline Control & 104 & 4.35 & 0.721 & & & \\
\hline Organization & & & & & & \\
\hline Instructor's explar & ear. & & & & & \\
\hline Treatment & 97 & 4.27 & 0.685 & 1 & 10.366 & $0.001 * *$ \\
\hline Control & 104 & 3.88 & 0.969 & & & \\
\hline The assignments & explained. & & & & & \\
\hline Treatment & 96 & 4.22 & 0.714 & 1 & 6.272 & $0.013^{* *}$ \\
\hline Control & 104 & 3.96 & 0.736 & & & \\
\hline Instructor spoke c & & & & & & \\
\hline Treatment & 97 & 4.49 & 0.580 & 1 & 6.561 & $0.011 * *$ \\
\hline Control & 104 & 4.26 & 0.710 & & & \\
\hline Instructor spoke a & speed. & & & & & \\
\hline Treatment & 97 & 4.43 & 0.691 & 1 & 3.134 & $0.078^{*}$ \\
\hline Control & 104 & 4.26 & 0.697 & & & \\
\hline Assignments & & & & & & \\
\hline Required readings & me. & & & & & \\
\hline Treatment & 97 & 3.56 & 0.924 & 1 & 2.853 & $0.093 *$ \\
\hline Control & 104 & 3.33 & 0.999 & & & \\
\hline Student and cour & tics & & & & & \\
\hline Level of interest in & this time. & & & & & \\
\hline Treatment & 97 & 3.52 & 0.937 & 1 & 5.103 & $0.025^{* *}$ \\
\hline Control & 104 & 3.19 & 1.080 & & & \\
\hline
\end{tabular}

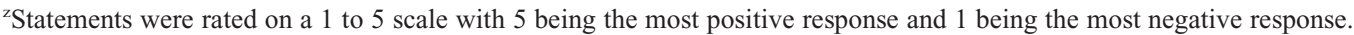

*Statistically significant at the 0.10 level.

*** Statistically significant at the 0.05 level.

way they felt while conducting class as well as their perception of the reaction and behavior of the class toward the presence of plants. A verbal interview was held with the professor of introductory psychology. Written interviews were received from the professors of the sophomore-level psychology and introductory sociology classes.

The professor of the introductory psychology course stated in an informal interview that she very much enjoyed the presence of plants in the classroom and felt the presence of plants might, unconsciously, have an effect on her presentation to the classroom. This supports other research that indicated that instructor mood could be improved by the presence of plants (Shibata and Suzuki, 2004) or that instructors could perceive a more comfortable learning environment (Dinsmore, 2003) in the presence of plants. Past research also indicates that plants can help increase attentiveness or decrease mental fatigue (Lohr et al., 1996).
Written interviews with the instructors of the sophomore-level psychology course and the introductory sociology course stated that they did not notice plants during instruction, although both instructors indicated they liked plants. The introductory sociology professor stated that class participation was higher in the treatment classroom, but absences did not seem to be affected. Other research states that plants can trigger positive emotions (Isen, 1990), which may help to encourage discussion in a classroom environment.

The sophomore-level psychology professor stated she felt attendance was better in the class with plants, although she did not know if it was the result of the plants or perhaps the later time of day. The instructor also felt class participation was better in the class with plants, although she named a number of variables unrelated to plants that might have affected that participation. She noted that class average on most tests was higher in the class with plants, again adding that other variables not related to plants could have affected scores. However, if this observation was true, it would support research findings that plants can positively affect a person's emotional state (Ulrich, 1981), which benefits cognitive functioning necessary for memory recall (Isen, 1990).

\section{Conclusions}

Results from the study found that interior plants appeared to have the greatest impact on students participating in the classroom environment that had no other natural elements. Results also showed that interior plants can be a suitable alternative in some cases to architectural elements such as windows. Research has found that passive encounters with nature can improve levels of satisfaction with job and home life and can affect mood and cognition (Kaplan and Kaplan, 1989; Sheets and Manzer, 1991; Shibata and Suzuki, 2004). This study supports 
other research showing that plants have value beyond aesthetics in interior environments (Dravigne et al., 2008; Liu et al., 2003; Lohr and Pearson-Mims, 2000; Lohr et al., 1996; Taylor et al., 2001), including promoting positive feelings in university students. More research should be conducted on the influence of plants on classroom instructors because, in interviews, one professor noted that she may have been unconsciously affected by the presence of the plants in the room. Because this factor was not specifically measured in this research, the impact of the plants on instructors' teaching may be a confounding factor in this research.

\section{Literature Cited}

Bennett, R. 1995. To the editor. J. Rheumatol. 22:273-274.

Borg, W. and M. Gall. 1989. Educational research: An introduction. 5th Ed. Longman Group, New York, NY.

Dinsmore, T.S. 2003. Classroom management. Marygrove College, Michigan. ERIC Document Reproduction Service No. ED478771.

Douglas, D. and R. Gifford. 2001. Evaluation of the physical classroom by students and professors: A lens model approach. Educ. Res. 43:295309.

Dravigne, A., T.M. Waliczek, R.D. Lineberger, and J.M. Zajicek. 2008. The effect of live plants and window views of green spaces on employee perceptions of job satisfaction. HortScience 43:183-187.

Fjeld, T., B. Veierstedb, L. Sandvike, G. Riisec, and F. Levyd. 1998. The effect of indoor foliage plants on health and discomfort symptoms among office workers. Indoor Built Environ. 7:204-209.

Frankel, M. 1983. Sampling theory, p. 21-67. In: Rossi, P.H., J.D. Wright, and A.B. Anderson (eds.). Handbook of survey research. Academic, San Diego, CA.

Frey, P., D. Leonard, and W. Beatty. 1975. Student ratings of instruction: Validation research. Am. Educ. Res. J. 12:435-447.

Gall, M.D., W.R. Borg, and J.P. Gall. 2006. Educational research: An introduction. 8th Ed. Allyn and Bacon, White Plains, NY.

Gowan, R. 1987. Plant effluvia. Changing notions of the effects of plant exhalations on human health in the eighteenth and nineteenth centuries. J. Gard. Hist. 7:176-185.

Hart, L. 1999. Human brain and human learning. Books for Educators, Inc., Black Diamond, WA

Isen, A. 1990. The influence of positive and negative affect on cognitive organization: Some implications for development, p. 75-94. In: Stein, N.L., B. Leventhal, and T. Trabasso (eds.). Psychological and biological approaches to emotion. Lawrence Erlbaum Associates, Hillsdale, NJ.

Kaplan, R. 1987. Basic statistics for the behavioral sciences. Allyn and Bacon, Upper Saddle River, NJ.

Kaplan, R. and S. Kaplan. 1989. The experience of nature: A psychological perspective. Cambridge University Press, Cambridge, NY.

Laviana, J., R. Mattson, and F. Rohles. 1983. Plants as enhancers of the indoor environment, p. 738-741. In: Pope, A. and L. Haugh (eds.). Proc. of the 27th Annual Meeting of Human Factor Society, Norfolk, VA.

Likert, R. 1967. The method of constructing an attitude scale, p. 90-95. In: Fischbein, M. (ed.). Readings in attitude theory and measurement. John Wiley and Sons, New York, NY.

Liu, M., E. Kim, and R. Mattson. 2003. Physiological and emotional influences of cut flower arrangements and lavender fragrances on university students. J. Therapeutic Hort. 14:18-27.

Lohr, V. and C.H. Pearson-Mims. 2000. Physical discomfort may be reduced in the presence of interior plants. HortTechnology 10:53-58.

Lohr, V., C.H. Pearson-Mims, and G.K. Goodwin 1996. Interior plants may improve worker pro- ductivity and reduce stress in a windowless environment. J. Environ. Hort. 14:97-100.

MeCornack, R. and M. McLeod. 2005. Gender bias in the prediction of college course performance. J. Educ. Meas. 25:321-331.

Robertson, A., M. McInnes, D. Glass, G. Dalton, and P. Burge. 1989. Building sickness: Are symptoms related to the office lighting? Ann. Occup. Hyg. 33:47-59.

Russell, H. and D. Uzzell. 1999. Green plants for the feel good factor. Interiorscape Magazine. 8 Mar. 2005. <http://www.interiorscape.com/ rentokil/>

Sheets, V. and C. Manzer. 1991. Affect, cognition, and urban vegetation: Some effects of adding trees along city streets. Environ. Behav. 23: 285-304.

Shibata, S. and N. Suzuki. 2004. Effects of an indoor plant on creative task performance and mood. Scand. J. Psychol. 45:373-381.

Taylor, A.F., F.E. Kuo, and W.C. Sullivan. 2001. Coping with ADD: The surprising connection to green play settings. Environ. Behav. 33:5477.

Think, M.K. 2003. University of San Francisco classroom and office standards and prototypes. San Francisco, CA. June 2008. <http://www. usfca.edu/planning_budget/space_planning committee/pdf/standards.pdfs.

Ulrich, R. 1981. Natural versus urban scenes: Some psychophysiological effects. Environ. Behav. 13:523-556.

Ulrich, R., R. Simons, B. Losito, E. Fiorito, M. Miles, and M. Zelson. 1991. Stress recovery during exposure to natural and urban environments. J. Environ. Psychol. 11:201-230.

Vitiello, A. 2001. Specifying interior planting can be subjective. Plants for People, Düsseldorf, Germany. 19 June 2008. <http://www.plantsfor-people.org $>$.

Wiers-Jenssen, J., B. Stensaker, and J. Grogaard. 2002. Student satisfaction: Towards an empirical deconstruction of the concept. Qual. High. Educ. 8:183-195. 